\title{
Investigation the Relationship between Urban Defenseless Spaces with Sense of Citizens Social Security Case Study: Tehran City
}

\author{
Reza Ali Mohseni \\ Sociology Associate Prof, Tehran Markaz Branch, Azad University \\ Akbar Talebpour \\ Sociology Assistant Prof, Grand Ayatollah Boroujerdi University; Email: talebpour110@ yahoo.com \\ Jafar Mikaeli \\ Sociology Phd Candidate, Tehran Markaz Branch, Azad University
}

\section{Doi:10.5901/mjss.2016.v7n5p241}

\section{Abstract}

\begin{abstract}
The relationship between urban space and the sense of social security of citizens nowadays is considered as one of the topics of urban sociology in sociology, these spaces can make a significant impact on the psychological security among citizens. Therefore this article aims to study the characteristics of urban space and its role in citizens' sense of security by using different theoretical sociology, social psychology and urban design such as; Monitoring the street, Jane Jacobs views, Cultural differences, Rapoport views, Defensible space, Newman, Broken windows, Wilson views, Situational crime prevention, Clarke views, Ray Jeffrey views, Spatial layout, and Hillier in 2015 in Tehran city. The study was based on survey and questionnaires. Research questionnaire has been examined dimensions of security in four components; financial, mental, physical and sexual security, with 28 items. A total of 400 citizens from Tehran population were selected as research sample society that comprised of five urban areas of North, South, East, West and center of Tehran city. The results showed, citizens sense of social secure in defense spaces more than from citizens sense of social secure in insecure spaces. The hypothesis test showed that the relationship between urban space and sense of security are significant differences in terms of the feeling of insecurity among the citizens in defenseless spatial and defense space can be seen. The result also showed; some defenseless spaces to the social and physical factors are potentially receptive to social problems and provide debugger and violent activities in Tehran selected areas.
\end{abstract}

Keywords: Sense of security, urban Spaces, Environmental and Physical planning, Defenseless Spaces.

\section{Introdution}

Development of physical and social dimensions of cities and become them to the centers of heterogeneous demographic, social and physical unevenness and urban Sprawl and yet inevitably have has a significant impact on urban life. In this century can be effected so that cities in the development of social and behavioral damage observed in urban communities. Increased urban violence underlying the behavioral and social insecurity, and the people who live close relations with their living environment is faced with difficulty (Jacobs,1981:35).

With the expansion of the city in modern era, and complications arising from urbanization, urban crime phenomenon was the subject of scientific research and various views were expressed on this issue. Some, like Chicago School directly note to the density and mobility of the population and cultural diversity are influencing social disorganization and others such as Jane Jacobs, Newman, Transyk focus on aspects of urban design and architecture and physical characteristics of the crime facilitator and insecurity(khamoushi:2008;1). The city with all its layers (physical form , space, movement and access bones of public spaces) can help to create a safe and secure environment and create social space oriented encourage citizens to pause gathering vice versa to Edward Hall; space can also be interpreted in terms of physical and social barriers created social space getaway (Hall:1997;122).

The lack of security, a sense of danger and fear of crime in urban areas to reduce the use of public areas without a sense of security and lack of efficiency of the urban environment, urban environment areas would not be citizens social interaction spans, So we can say urban security in today's world one of concerns issues in architecture, urbanism and 
sociology. Although the crimes are not confined to the cities, but most are in cities and most crimes are happening in the streets, However if the architectural design of buildings and streets and urban neighborhoods can play a role in the crime rate and insecurity? Some urban areas due to many factors including social and physical potential for damage embraces social and acts contrary to the norms of society (Fiyalkof, Yunkel; 2002:92). According to a Zukin; people in urban spaces are facing with a variety of threats such as crime, terrorism, pollution, earthquakes and floods, interfere with the movement of vehicles and pedestrians. So from his perspective city isn't intersection to cross, but a settlement for life. City streets and spaces are not passing place but are the places of residence.

Research results regarding defenseless spaces and sense of insecurity shows these place to deny people's access, makes access restrictions in urban areas, decline of the public sphere to follow and public space loses its attractiveness to gather citizens together in the particular places (Modiry;2006:12).

Though it certainly can be argued that sociological variables in explaining phenomena such as violence and antisocial behavior have priority, but human behavior varies in different space environments. Nevertheless, skeletal and spatial settings in the sociological analysis should not be ignored. Spatial and skeletal settings can be a precursor to a series of social phenomena. The present study in response to the following fundamental question arises to what extent urban defenseless spaces is important to feel citizens securities? and How much is the contribution of urban areas to feel the security of citizens?

\section{Theoretical Framework}

Chicago School scholars among the first ones to point out the city and the city existing disorganizations. Robert Park and Burgess believed that the transition region of the cities due to high levels of population mobility, instability of population, immigration, the anonymity of people, destroyed homes, crowds can be seen high rates of crime and the offenders(Ahmadi;2008:83). McKay believed; deviant behavior occurs in this part of town because that informal social control such as monitoring public opinion public not strong enough to prevent the emergence and incidence of abnormal behaviors (Ibid;84).

Louis Wirth in his famous essay "urbanism as a way of life" defines the city as; relatively large camp, dense, and permanent that peoples socially and culturally non-homogenous. According to him the urban life replaces the official tool of social control with informal tools, massive urban citizens replaces official competitive mechanism controlling with conscience(Sarvestani;1990:206) .

David Chapman believes the physical properties of space are likely to influence the behavior because the situation and the space can be effective on comfort or discomfort(chapman;2007:179). Jacobs referred security issue, as well as spatial and inhibiting factors, according to him it is a sign of a successful city that person in the streets and other areas of the city that is full of strangers feel secure and confident and should not be feel themselves threatened(Jacobs;1981). Jacobs emphasize the role of residents - eyes on the street - and zones that care for them, If people see that control will be applied the feeling of security will produce. This model helps us that to explain the relationship between the environment and fear of crime and insecurity in two ways ; first through direct way means that symptoms of crime and insecurity can indicate a real risk, second through indirect way means that fear of crime is the result of characteristics of the urban environment or the same show(Jacobs;1961).

Kevin Linch gives great importance to the mental patterns and people's perception and his efforts are understanding the relationship between physical space and mental space of memories(Lonch;2004:265). Roger Trancik in his book; recovering lost spaces pay attention to the use of unused spaces or spaces that do not use enough. In his view, unused urban spaces are spaces that have no positive impact on the environment and users: spaces that are poorly defined, measurable boundaries do not create the elements of continuity. These spaces are surrounding land remains high buildings, fields without use, parking and land that is on the fringes of ways and without human presence have been abandoned and nobody cares the content of these spaces (Trancik;1986:118). Rappa port searches the formation of living spaces in people culture and knows the difference between physical space as a result of cultural difference.

The first discussions about the relationship between crime and urban space was formed in the city of Chicago and the Chicago School in the 1920 and 1930s, but the first Coherent theories that stressed to the environmental aspects of crimes were formed in the 196's ,few of these theories are mentioned below;

\subsection{Defensible Space Theory}

Defensible spaces is within design theory and refers to the settlements experience in use of space. The main source of 
theory was observations of Oscar Newman's of spaces and places. Territoriality, surveillance, boundary definition, image and social space are four principles of this theory.

\subsection{Broken Windows Theory}

Broken windows theory was proposed by Wilson \& clinic. This theory suggests that there is a direct link between the turbulent and chaotic streets and buildings and crime. If even a broken window in a neighborhood without repair, to remain the same time can be a sign and a message to potential criminals that the police and the neighborhood not to ignore the location situation. Broken windows may be along to other signs of chaos like; dirty walls, crash, car bills, garbage and... then, with such an area, begins the process of gradual of degradation.

\subsection{Crime Prevention Through Environmental Design Theory}

Crime prevention through environmental design theory was designed with distinction from the core theory untenable theory of architectural spaces by Ray Jeffrey, in response to the ineffectiveness of the criminal justice system and crime prevention. Jeffrey in 1970 focused on the relationship between man and his environment so as to find a way to overcome the crime through the environment. According to this theory, in addition to the residential units that will be emphasized in the theory of defensible spaces extended on spaces and other land uses.

\subsection{Situational Crime Prevention Theory}

In 1997,Clarke offered matrix of 16 techniques to reduce crime opportunities that presented in the table below which has emphasized on four principles; increases the burden, reduce the reward, increases the risk and excuses eliminate (Clarke;1996:121).

Table 1. Clarke's16 Techniques to Reduce Crime Opportunities

\begin{tabular}{|c|c|c|c|}
\hline Increases the Burden & Reduce the Reward & Increases the Risk & Excuses Eliminate \\
\hline $\begin{array}{l}\text { 1. Hard target; Central Locking } \\
\text { Device, Car locking ,Camera }\end{array}$ & $\begin{array}{l}\text { 5. The input and output camera; } \\
\text { Automatic Doors, Control Bags } \\
\text { and Back packs, Labels for } \\
\text { Goods }\end{array}$ & $\begin{array}{l}\text { 9. Relocation purposes; Car } \\
\text { Recordings Panels, Shelters for } \\
\text { Women, Encryption Mobile } \\
\text { Phones }\end{array}$ & $\begin{array}{l}\text { 13. Regulation; } \\
\text { Statements to customers, } \\
\text { Highlighting cases of harassment. } \\
\text { Hotels Registration }\end{array}$ \\
\hline $\begin{array}{l}\text { 2. Access control; } \\
\text { Control of entry and exit of } \\
\text { vehicles in parking lots, Installing } \\
\text { Cameras at the Entrance }\end{array}$ & $\begin{array}{l}\text { 6. Official Monitoring; CCTV } \\
\text { Purple, Theft Alarm, Security } \\
\text { Guards }\end{array}$ & $\begin{array}{l}\text { 10. The identity of the Assets; } \\
\text { Issuance of Permits for } \\
\text { Vehicles, Having Property } \\
\text { Identification Number }\end{array}$ & $\begin{array}{l}\text { 14. Raising awareness; Installing } \\
\text { Speedometer }\end{array}$ \\
\hline $\begin{array}{l}\text { 3. Misleading Offenders; Insert the } \\
\text { Bus Stop, Specified Locations, } \\
\text { Bistro, Openness of the Area and } \\
\text { the Street }\end{array}$ & $\begin{array}{l}\text { 7. Monitoring by Staff; Installed } \\
\text { a Pay Phone, Traffic Wardens, } \\
\text { Surveillance }\end{array}$ & $\begin{array}{l}\text { 11. Reduction Tempting } \\
\text { Situations; Mixed Gender, } \\
\text { Private Parking, } \\
\text { Fast Repair }\end{array}$ & $\begin{array}{l}\text { 15. Control Laws; The Legal Age } \\
\text { for Drinking Alcohol, Blood } \\
\text { Alcohol Control, TV Channels } \\
\text { Device Control }\end{array}$ \\
\hline $\begin{array}{l}\text { 4. Control the Identification Card; } \\
\text { with photo, Gun Control Licensed, } \\
\text { Caller ID Device }\end{array}$ & \begin{tabular}{|l|} 
8. Natural surveillance; \\
Defensible Space, Clear \\
Streets, Taxis with Identification
\end{tabular} & $\begin{array}{l}\text { 12. The Elimination of Profits; } \\
\text { Electronic Tags on Goods, PIN } \\
\text { Code, Wipe the Walls of Posts }\end{array}$ & $\begin{array}{l}\text { 16. Easy Conditions; Books out of } \\
\text { Libraries, Public Restrooms, } \\
\text { Installing Trash }\end{array}$ \\
\hline
\end{tabular}

In the early 90s a new approach environmental criminology arose which led to the emergence of new concepts and trends in this area, these concepts include two theories: Space Syntax Theory and New Urbanism respectively.

In this study, has been used the combination of two major approaches; location-based theory and demographic explanation.

\section{Research Methodology}

The research methodology of this research was survey method and to measure variables using a questionnaire. Research hypotheses was below hypotheses;

1. The feeling of insecurity citizens in space with defense is more than defenseless areas.

2. Feelings of financial insecurity (somatic insecurity, honor insecurity and psychological insecurity) citizens in spaces with defense is more than defenseless areas. 
Measuring instrument for navigation, a 61-item questionnaire that, has been done among a sample size of 400 person's, including 182 female and 218 males that were in sample places. The sample place were showed in table number2 in below.

Table 2. Sample Spaces Regions

\begin{tabular}{|l|c|l|l|}
\hline Area & Region & Spaces with Defense & Defenseless Space \\
\hline North & 2 & Nahjolbalagheh Park, Iranzamin Street & Mellat Park, Nosrat Street, Sanaat Square Pedestrian Overpass \\
\hline West & 5 & $\begin{array}{l}\text { Boustan Mall, Sattarkhan Pedestrian } \\
\text { Overpass }\end{array}$ & $\begin{array}{l}\text { Sadeghiyeh Metro Station, West Passenger Terminal, Ekbatan } \\
\text { Residential Complexes }\end{array}$ \\
\hline East & 4 & Police Park, Amin Street, Hojr Street & $\begin{array}{l}\text { East Passenger Terminal,Shahid Bagheri Autoban, Eshragh Metro } \\
\text { Station, Lavizan Park }\end{array}$ \\
\hline Center & 12 & $\begin{array}{l}\text { Sepahsalar bazaar, Mojahedin Street, } \\
\text { Iran Street, }\end{array}$ & Naserkhosrow Street, Pamenar Alleys, Emam Metro Station \\
\hline South & 19 & Velayat Garden & Abdolabad Bazaar \\
\hline
\end{tabular}

\section{Findings}

The results are in both descriptive and inferential findings, which is discussed below;

\subsection{Descriptive Findings}

\subsubsection{The mean of financial insecurity and somatic insecurity Items}

As can be seen in the tables below $(3,4)$ in the all items index of financial insecurity, citizens insecurity in defenseless spaces is more than defense spaces, the overall average index of financial insecurity in defenseless spaces is more than defense spaces. The average items index of somatic insecurity also shows in all the statements of this index citizens insecurity in defenseless is more than defense spaces and the overall average index of somatic insecurity in defense spaces is more than defenseless one.

Table 3. The average items index of financial insecurity

\begin{tabular}{|l|c|c|}
\hline Dimensions of financial insecurities & Defenseless Spaces & Spaces with Defense \\
\hline Alarmed by the having expensive things & 3.5 & 3.23 \\
\hline Concern with theft or robbery & 3.19 & 2.92 \\
\hline Fear of extortion and blackmail evil people & 2.89 & 2.55 \\
\hline Fear of hiding or bag snatch thieves & 2.77 & 2.28 \\
\hline Prefer to don't having for jewelry & 3.79 & 3.59 \\
\hline Observing theft of property of citizens & 3.46 & 2.78 \\
\hline Existence beggars and itinerant people & 3.04 & 2.46 \\
\hline Total & 3.2 & 2.83 \\
\hline
\end{tabular}

Table 4. The average items index of somatic insecurity

\begin{tabular}{|l|c|c|}
\hline Dimensions of somatic insecurities & Defenseless Spaces & Spaces with Defense \\
\hline The safe of place & 3.02 & 3.63 \\
\hline Concern with dangerous people attack & 2.91 & 2.39 \\
\hline Observing conflicts in outer space & 3.08 & 2.46 \\
\hline The anxiety of children & 3.79 & 3.92 \\
\hline Homeless and stroller observing & 3.05 & 2.41 \\
\hline The lack of control and necessary supervision to ensure the security in place & 2.98 & 2.55 \\
\hline Others help probability in case of disturbances & 3.32 & 3.42 \\
\hline Total & 3.16 & 2.79 \\
\hline
\end{tabular}




\subsubsection{The mean of psychological insecurity ltems}

As can be seen in the tables below $(5,6)$ in the all items index of psychological insecurity, citizens insecurity in defenseless spaces is more than defense spaces, the overall average index of psychological insecurity in defenseless spaces is more than defense spaces. The average items index of honor insecurity also shows in all the statements of this index citizens insecurity in defenseless is more than defense spaces and the overall average index of honor insecurity in defense spaces is more than defenseless one.

Table 5. The average items index of psychological insecurity

\begin{tabular}{|l|c|c|}
\hline Dimensions of psychological insecurities & Defenseless Spaces & Spaces with Defense \\
\hline Sense of security and comfort of being in place & 3.29 & 3.68 \\
\hline Observed Drug & 2.46 & 2.13 \\
\hline Observed thugs yelling or hooliganism & 2.47 & 2.07 \\
\hline Willingness to reengage in this place & 3.43 & 3.76 \\
\hline Unwillingness to attend the evening hours at this location & 3.69 & 3.37 \\
\hline Reluctance to communicate with strangers and unknown & 3.46 & 3.12 \\
\hline The lack of clean and dirty spatial & 2.73 & 2.03 \\
\hline Total & 2.86 & 2.44 \\
\hline
\end{tabular}

Table 6. The average items index of honor insecurity

\begin{tabular}{|l|c|c|}
\hline Dimensions of honor insecurities & Defenseless Spaces & Spaces with Defense \\
\hline Jog men to women & 3.44 & 2.96 \\
\hline Taunting women by some people & 3.80 & 3.69 \\
\hline Existence people in the case of help & 2.60 & 2.59 \\
\hline Look at strangers and inappropriate & 3.43 & 2.85 \\
\hline Alarmed by the presence of lewd and corrupt people & 2.67 & 2.81 \\
\hline Hear indecent and insulting & 3.04 & 2.19 \\
\hline Unwillingness to frequent appearances in space & 2.90 & 2.23 \\
\hline Total & 3.21 & 2.81 \\
\hline
\end{tabular}

\subsection{Analytical Findings: Test the Hypothesis}

T-tests were used to test hypotheses, test results are shown in tables 7 and 8 below;

Table 7. First Hypotheses Test

\begin{tabular}{|l|l|c|c|c|c|c|}
\hline Dependent Variable & City Spaces & Sample Size & Mean & S.t.D & S.t.D.E & sig \\
\hline Insecurity & Defenseless Spaces & 257 & 87.16 & 16.7 & 1.043 & \multirow{2}{*}{000} \\
\cline { 2 - 7 } & Spaces with Defense & 140 & 76.32 & 15.5 & 1.313 & \\
\hline
\end{tabular}

Due to a significant degree and the mean of insecurity in defenseless spaces and is specified in the table above that Tehran's defenseless spaces have given less secure to citizens and citizens in spaces with defense have feel more security.

Table 8. Second Hypotheses Test

\begin{tabular}{|l|l|c|c|c|c|c|}
\hline Dependent Variable Dimensions & City Spaces & Sample Size & Mean & S.t.D & S.t.D.E & sig \\
\hline Financial Insecurity & Defenseless Spaces & 257 & 22.5 & 5.53 & .34 & \multirow{2}{*}{000} \\
\cline { 2 - 7 } & Spaces with Defense & 140 & 19.81 & 5.86 & .39 & \\
\hline \multirow{2}{*}{ Somatic Insecurity } & Defenseless Spaces & 257 & 22.12 & 4.44 & .27 & \multirow{2}{*}{000} \\
\cline { 2 - 7 } & Spaces with Defense & 140 & 19.53 & 4.09 & .34 & \multirow{2}{*}{.30} \\
\hline Psychological Insecurity & Defenseless Spaces & 257 & 20.08 & 5.16 & .32 & \multirow{2}{*}{000} \\
\cline { 2 - 7 } & Spaces with Defense & 140 & 17.28 & 4.66 & .39 & \\
\hline
\end{tabular}




\begin{tabular}{|l|l|l|l|l|l|l|}
\hline \multirow{2}{*}{ Honor Insecurity } & Defenseless Spaces & 257 & 22.51 & 5.21 & .32 & \multirow{2}{*}{000} \\
\cline { 2 - 7 } & Spaces with Defense & 140 & 19.68 & 5.29 & .44 & \\
\hline
\end{tabular}

Due to a significant degree and the mean of financial, somatic, psychological and honor insecurity dimensions in defenseless spaces and is specified in the table above that in all dimensions Tehran's defenseless spaces have given less secure to citizens and citizens in spaces with defense have feel more financial, somatic, psychological and honor security.

\section{Conclusion}

In this study, a sense of security in four dimensions (the psychological sense of security, a sense of financial security, somatic security and honor security) was measured, the results showed that in all four factors mentioned citizens sense of security in the Tehran's spaces with defense significantly more than defenseless spaces. This subject also took into consideration in the explanatory theories, in terms of spatial approach assumes that physical and environmental conditions in some parts of Tehran can be taken to effectively prevent urban violence and personal safety sure. In this approach, it is thought that there is a relationship between location and behavior and behavior can be modified due to the location impact. Removing hidden corners, hiding places, convenient way to escape is to prevent criminal behavior ,so that was observed in Tehran spaces; places that were designed to fit the rise of crime was less and citizens feel satisfied. In fact, physical environment able through increased control, surveillance urban spaces, availability and involvement of citizens in the use of space, increase the sense of security. This approach has emphasized in this study and will empower the city's physical environment of physical control and inhibitory criminal behavior. This study also showed that fear of victimization on defenseless spaces and consequently increasing the sense of security has been on the decline. Coordinates of defenseless spaces in Tehran as Terminals or dark narrow streets and alleys has confused citizens and encountered them with anxiety and fear, is leading to increased insecurity and vice versa safe space and spaces with defense are sake of security and deterrence of providing opportunities. Other findings show that citizens in select of city regions as insecure areas in the entire city have relative agreement. Most of them in different parts of the city evaluated unfinished and dilapidated buildings, deserted and dark streets, crowded places as spaces with low security. According to Jacobs that the distinction between public and private space emphasizes the role of residents as the eyes in the street and knows construction and design a regulatory agent that the street should be opened, that in accordance with the result of main hypothesis is that urban spaces from the perspective of the different security surveillance.

Rappaport search the formation of biological basis in the culture of the peopleand knows space and physical space differences arising from the differences in culture. The results showed that the differences sense of security in areas of North, South, East, West and Center, according to urban amenities were not significant and the main hypothesis is reinforced. Newman's defensible space (principle of territoriality, surveillance, boundary definition, image and social space), which seeks to discipline up too much space and the social role of space in the residents feeling of insecurity or extreme fear them. The results also showed a sense of social security is greatly influenced by the type of urban space that Newman's theory, especially theoretical ideas is consistent with Newman's somatic security, is supported.

Wilson broken window theory suggests there are a possible relationship between the turbulent and chaotic streets and buildings and crime and insecurity. The results revealed that sense of security, especially the sense of psychological security is affected by the urban fabric of spaces, In such a way that the defenseless areas of Tehran city provide little psychological sense of security for the citizens of Tehran and urban space with defense makes citizens less psychological sense of insecurity.

\section{Discussion}

As the research demonstrated in Tehran, defenseless spaces in all aspects of insecurity are worse than spaces with defense, which are considering the important issue of security in the spaces. It seems defenseless spaces in Tehran are faced with insecurity and need to show special attention to this matter and to reduce the consequences of this insecurity.

Given the importance of this phenomenon are two-fold when we know that four insecurity forms in defenseless spaces which Tehran is faced with them have two special function in normal and crises times. In normal times these insecurities do as criminal environments and crimes could be exports from these areas to other regions that leads to increase in urban crimes. But in crisis times, these spaces can act as centers of urban crisis that are leading to more insecurity of city. Therefore it is necessary that municipal officials with knowledge of the dual functions of these spaces must act to reduce insecurity in these spaces. 


\section{Suggestions}

City defenseless have characteristics that changes even in every days time and thus makes space defenseless and paving the way for a certain kind of urban violence and consequently feel insecure spaces, so the solutions should be somewhat variable social and physical-social characteristics should be considered. In addition it should be noted that manipulate partial or total change in characteristics due to economic, social and cultural restrictions be not possible.

Some urban spaces in Tehran are the product of bad planning and others are changed over time spaces that are defenseless. Accordingly, solutions and suggestions should be a top priority to reduce the severity or reduce the severity of defenseless and helpless too. However, the following suggestions are offered to improve the urban condition in Tehran;

1- Visual sighting in designing and manufacturing spaces to the right and the right amount of attention from different angles is being seen, to avoid from the side view of buildings, the maze of the front and rear due to deterioration of the buildings along the streets as much as possible.

2- Most insecure areas are limited regulatory opportunities and in some cases have no opportunity to monitor and control. This feature greatly increase opportunities to reduce regulatory environments have windows, doors and balconies overlooking the embedded space and physical obstacles such as trees and leaves reduced.

3- The continued absence of people in some areas is the factor's of insecurity. Modifications to these conditions, can be changes in physical conditions and using of space, reduce the deserted space. At the time of localization activities and the establishment of spaces such as parks, be careful which to be able to attract a significant number of peoples at most hours, or by moving an index of activity in a space can be helped to connect people with space and activity space, reduce from the poverty of space.

4- The passage of the overpass should be visible and not wearing by the paintings and other extensions.

5- Public transport stations, to increase safety must be installed in visible places and all stations have provide appropriate shelter lighting and climate comfort.

6- Must be avoided from putting the urban equipment and furniture at the intersection and malls that led to the closure and reduce of pedestrian safety.

7- In locating parks should be care taken that corners and excessive roughness not be too much. In addition, in the park design, taking into account various behavioral commands (such as walking, sitting, resting, etc.) is essential.

8- In order to recognize the urban space and preserve collective memories, protecting valuable and memorable elements remaining in direction is required that help to increase the shelf life of the people in the neighborhood and leads to residential stability.

9- Collective memory management (the concept of Mourice Halbowaks) help to urban design. Use the materials, forms and elements that somehow evokes the past and reflect the history of the city is essential. Diary use the links to individual memory with locations for the action and experience and contributes to population stabilization.

\section{References}

Ahmadi.Habib (2012) Sociology of Deviance. Second Edition . Tehran; Samt Press.

Brantingham(1981) Crime. Space and Criminological Theory, Beverly Hills Sage Publication.

Berman.M(1984) The Signs in the street :A Response to Perry Anderson. New Left Review .123-144.

Brooks, M(2002) Planning Theory for practitioners. American Planning Association; Chicago.

Clarke.R.V(1997) Situational Crime Prevention: Successful case study. New York; Sage Publication.

Colquhoun.(2004)Design out Crime .Creating Safe and Sustainable Communities . Oxford; Architecture Press.

Coleman ,C(1990)Utopia on Trial .revised edition. London ; Hilary shipman.

Cornish. D .B, Clarke .V(1986)The Reasoning Criminal. Rational Choice Perspectives on Offending. NewYork NY; Spring- Verlag.

Ferraro.K,LaGranye,R.(1995)"The Measurement of Fear of Crime" Sociological Inquiry,Nro,57,pp70-101.

Fiyalkof, Yunkell (2013) Sociology of City. Translated by Nikghohar Abdolhossein. Tehran ; Agah Press.

Grabosky(1995)Fear of Crime and fear reduction Strategies. Australian Institute Of Criminology. Canberra.

Hall.E.T.(1997)The Hidden Dimension . Garden city; Doubleday.

Hillier.b.(1996) Space is the machine .Cambridge university press.

James Glay Moltz(2011) The Politics of Space Security. Stanford University Press.

James Glay Moltz(2014) Conflict and Cooperation in Space. Columbia University Press. 
Jeffry.C.R.(1977) Crime prevention Through Environmental Design. Beverly Hills; Sage Publication.

Kim Gurney(2015) The Art of Public Space: Curating and Re-imagining the Ephemeral City. London; UK :Palgrave Macmillan. Lindstrom (2013) Social Capital and Sense of Insecurity Sweden-social scienc. Vol.56.pp1111-1120

Lockwood.P(2007)Mapping Crime in Savannah. Tehran ;Saye publication.

Jacobs.j.(1981)The Death and Life of Great American cities. New York; Sage Publication.

Mayhew.p.(1981)Crime in Public View :surveillance and crime prevention Environmental Criminology . Beverly Hill ; Sage Pub. Mitar, Miran(2002), Assessment of societal security in Recent Past and Today .www.ncirs. org.

Newman.(1972).Defensible Space; Crime Prevention through Urban Design. New York; Macmillan Co.

Newman Oscar (1996) Creating Defensible Space Department of Housing and Urban Development. University of Michighan. Oxley,J,(2005) Crime Opportunity Profiling of Streets(cops) Building Research Establishment.UK; Garstaon Walford.

Painter.k\& Farrington, D(1997)The Crime Reduction Effect of Improved Street Lighting. Guilderland, NY: Harrow and Heston. Poyner,M(2006)Crime- Free Housing in the21s Century ucl jill dande Institute of Crime science; London.

Sarvestani, Rahmatollah(1990) Human \& Urbanization. Social Sciences Qorterly.VOL12.

Schneider, R,(2007)Crime Prevention and the Built Environment. London; Routledge Press.

Trancik, Roger (1986) Finding Lost Space . New York; Sage Publication.

Wilson. J.(1982) .Broken Windows :The police and Neighborhood Safety The Atlantic Monthly (March):29-83.

Zukin.s(1995) The Culture of Cities . NewYork; Blackwell publishers. 